\title{
La manipulación temporal en los tráileres de cine: articulación de un nuevo tiempo narrativo
}

\author{
Eva Gil Pons \\ Universidade da Coruña \\ eva.gil@udc.es
}

Recibido: $11 / 07 / 2012$

Aceptado: 15/10/2012

\begin{abstract}
Resumen para generar un texto de naturaleza promocional partiendo de otro puramente cinematográfico. tiva, Golden Trailers Awards

\section{Temporal Manipulation in Movie Trailers: Articulation of a New Narrative Time}

La finalidad de este artículo es la de determinar cuáles son las tendencias actuales en la articulación discursiva temporal de los tráileres cinematográficos. La presente investigación toma como punto de partida el avance de cine como una modalidad de discurso audiovisual particular en el que convergen elementos cinematográficos y promocionales. Se analizan los mecanismos de construcción temporal de los tráileres con el objetivo de determinar de qué modo se configura el tiempo narrativo en los avances

Palabras clave: Tráiler cinematográfico, Narratología, Manipulación temporal, Fragmentación narra-

\begin{abstract}
The aim of this paper is to identify current trends in temporal discursive articulation of film trailers. This research takes into account the film trailer as a particularly audiovisual speech in which cinematographic and promotional items converge. Mechanisms of temporary construction of trailers are analysed in order to determinate how narrative time is used to generate a promotional text based on a purely cinematographic text.
\end{abstract}

Keywords: Film trailers, Narratology, Handling time, Narrative fragmentation, Golden Trailers Awards.

\section{Referencia normalizada}

GIL PONS, Eva (2012): "La manipulación temporal en los trailers de cine: Articulación de un nuevo tiempo narrativo". Estudios sobre el mensaje periodístico. Vol. 18, núm. especial octubre, págs.: 433441. Madrid, Servicio de Publicaciones de la Universidad Complutense.

Sumario: 1. Introducción. 2. Metodología. 3. Desarrollo: Historia, relato y narración; 3.1. Análisis del tiempo narrativo; 3.2. Orden; 3.3. Duración; 3.4. Contracción temporal; 3.5. Expansión temporal; 3.5.1. Digresión reflexiva; 3.5.2. Pausa; 3.5.3. Expansión y reducción temporal a través de efectos especiales; 3.6. Frecuencia. 4. Conclusiones. 5. Referencias bibliográficas.

\section{Introducción}

El avance cinematográfico se encuadra en un marco promocional cinematográfico posicionándose como uno de los elementos principales de la campaña de una película. Tomando como referencia este contexto, la investigación supone un acercamiento a este formato audiovisual que ha devenido en los últimos tiempos un producto cultural cuyo valor trasciende lo meramente publicitario y que se caracteriza por manifestar un valor artístico vinculado a la propia evolución de la industria del cine. La celebración en los últimos tiempos de los festivales Golden Trailer Awards y Key Art Awards, que premian la creatividad de estos textos, es una muestra de la consolidación y la relevancia que ha adquirido esta práctica promocional como ente autónomo. 
El tráiler se configura como "un umbral, un lugar de acceso al film, como un anticipo del disfrute que está por venir" (Regosa, 2003: 12) ${ }^{1}$. Este hecho determina la naturaleza transtextual ${ }^{2}$ de este texto, pero a la vez el avance reivindica su propia autonomía a través de diversas manifestaciones. Así, el tráiler se dirige a una instancia espectadora diferente a la de la película, propone un nuevo concepto de autoría, introduce elementos puramente retóricos que no se revelan en el film y plantea al espectador una nueva relación textual. La manipulación temporal adquiere un papel determinante en esta nueva relación textual entre el tráiler y el film promocionado.

El discurso que se estudia en la presente investigación cuenta con la particularidad de que en él intervienen dos historias distintas, la del propio tráiler y la de la película, que no tienen que coincidir necesariamente. En las siguientes páginas se procede a un análisis pormenorizado de las técnicas discursivas con el objetivo de reflexionar acerca de la forma narrativa de este tipo de minificción audiovisual. El objetivo es determinar si los trailers poseen una coherencia discursiva propia generada a partir de la resignificación y recontextualización de las secuencias de la película a partir del montaje persuasivo.

\section{Metodología}

Con el objetivo de determinar de qué modo se configura el tiempo narrativo en los avances, se emplea el instrumental analítico que proporciona la narratología tomando como punto de partida las aportaciones de diversos autores como Gérard Genette, Chatman, Bal o, en el ámbito de la narrativa audiovisual, André Gaudreault y François Jost. El interés principal del trabajo es el estudio del propio relato, es decir, la manera de narrar los acontecimientos de la película en el tráiler, centrándose en el estudio de la temporalidad.

Por lo que respecta a la selección de la muestra de análisis que compondrá la investigación se ha atendido a un factor externo. Se toma una muestra de trailers cinematográficos procedentes del Festival Golden Trailers Awards (GTA) 3 para detectar cuáles son las tendencias actuales en la articulación narrativa de los avances cinematográficos. Para ello, se analizan los trailers vencedores de la categoría absoluta de este festival, conocida como Best of show, delimitando la muestra a los avances de naturaleza metonímica ${ }^{4}$.

1 Traducción propia

2 Se atiende a la definición propuesta por Genette de transtextualidad como la "relación de copresencia entre dos o más textos" o "presencia efectiva de un texto en otro".

3 Los Golden Trailers Awards, un festival anual que premia a los mejores avances del año y cuyo jurado lo conforman miembros de la industria: directores, productores, distribuidores, actores, guionistas, creativos publicitarios y críticos de cine.

${ }^{4}$ Para la selección de la muestra de la investigación se atiende a los avances metonímicos por ser la tendencia predominante en los GTA y en la producción general de avances, especialmente en la industria de Hollywood. El método de análisis narrativo propuesto se dirige a este tipo de trailers de condensación narrativa que emplean material del film promocionado y que representan la práctica totalidad de los trailers actuales. Por ello, en el análisis se han omitido los dos únicos tráileres metafóricos, Requiem for a dream y The Stepford Wives. 
Tabla 1 Trailers vencedores de la categoría Best of show de los GTA(elaboración propia)

\begin{tabular}{|l|c|c|}
\hline Tráiler & Género del film & Tipo de Producción \\
\hline Matrix & Ciencia ficción & Comercial \\
\hline Requiem for a dream & Drama & Independiente \\
\hline The Royal Tenembaums & Comedia dramatica & Comercial \\
\hline About Schmit & Comedia / Drama & Comercial \\
\hline The Stepford Wives & Comedia & Comercial \\
\hline Mission: Imposible III & Acción / Thriller & Comercial \\
\hline $\mathbf{3 0 0}$ & Acción / Fantasía & Comercial \\
\hline The Dark Knight & Acción / Drama & Comercial \\
\hline Star Trek & Ciencia Ficción / Acción & Comercial \\
\hline The Cove & Documental & Independiente \\
\hline La red social & Drama & Comercial \\
\hline
\end{tabular}

\section{Desarrollo: Historia, relato y narración}

El tráiler cinematográfico, como cualquier relato, plantea dos temporalidades: la de los acontecimientos que se narran y la relativa al propio acto de narrar (Gaudreault y Jost, 1995: 112). Estas temporalidades se articulan en tres niveles diferentes: el orden, la duración y la frecuencia. La temporalidad en el tráiler adquiere una relevancia especial en el análisis narrativo, pues estos tres niveles se conjugan para ofrecer, en menos de tres minutos, un programa narrativo de carácter persuasivo creado a partir de otro estructurado a priori, el de la película promocionada.

Por lo que respecta a la relación propuesta por Genette entre historia, relato y narración, existe una serie de regularidades en todos los tráileres analizados. Comenzando por el elemento del relato, es decir, los acontecimientos tal y como se presentan al espectador, todos ellos ofrecen una estructura narrativa tradicional basada en planteamiento-nudo-desenlace. Los trailers comienzan identificando el personaje protagonista de manera clara y su misión en la historia. A continuación, se presentan los acontecimientos nucleares que sirven de puntos de anclaje para dotar a la historia de una estructura coherente. La acción tiende a singularizarse (nuclearización diegética), obviando normalmente tramas secundarias. La unidad de acción determina el programa narrativo del protagonista y el origen del conflicto y la intriga.

Una de las características fundamentales del relato en los tráileres analizados es la presencia del suspenso narrativo en la organización estructural de los avances. Se produce una ausencia de epifanía narratorial, consecuencia de la naturaleza promocional del texto, que corresponde establecerla al espectador. Éste decide concluir o no la experiencia narrativa propuesta en el tráiler que culminará en el film promocionado en función de si el avance ha conseguido el anclaje del espectador implícito.

Por lo que respecta a la historia, la ordenación cronológica de los acontecimientos, resulta conveniente señalar que es en este elemento donde el tráiler muestra su mayor grado de especificidad como texto promocional. El discurso del tráiler, a diferencia de otros textos publicitarios, ofrece una historia que se articula a partir de la historia narrada por otro discurso audiovisual. Es decir, la historia del tráiler vende otra historia, manteniendo "una relación de contigüidad con el objeto al que representan" (Dorna- 
leteche, 2009: 8). Los avances generan nuevas historias a partir de otras preestablecidas en un discurso anterior

El tercer elemento de análisis textual es la narración, que hace referencia al hecho en sí de contar, al "proceso a través de cual se enuncian los contenidos de la historia en el relato" (Canet y Prósper, 2009: 22). En este sentido, los avances analizados tienen una duración de entre 2' 02" (The Royal Tenembaums) y 2' 27" (La Red Social). Esta circunstancia los encuadra dentro de la categoría del theatrical trailer, que tienen una duración de entre 1'50" y 2'30" (duración máxima pactada entre los estudios y los exhibidores). El theatrical trailer es precisamente el tráiler que, debido a su duración, puede ofrecer la trama principal de la historia de la película promocionada, la evolución del personaje protagonista y la presentación de los secundarios.

Tabla 2: Duración de los tráilers analizados (elaboración propia)

\begin{tabular}{|c|c|c|c|}
\hline Tráiler & Género & Año & Duración \\
\hline Matrix & Ciencia Ficción & 2000 & $2,31 ”$ \\
\hline The Royal Tenembaums & Comedia dramática & 2002 & 2'02” \\
\hline About Schmit & Comedia / Drama & 2003 & $2^{\prime} 28 ”$ \\
\hline Mission: Imposible III & Acción / Thriller & 2006 & 1'47” \\
\hline 300 & Acción / Fantasía & 2007 & 2'10" \\
\hline The Dark Knight & Acción / Drama & 2008 & 2'06" \\
\hline Star Trek & Ciencia Ficción / Acción & 2009 & 2'09" \\
\hline The Cove & Documental & 2010 & $2 ' 10 "$ \\
\hline La red social & Drama & 2011 & $2^{\prime} 27^{\prime \prime}$ \\
\hline
\end{tabular}

\subsection{Análisis del tiempo narrativo}

La manipulación temporal es uno de los mecanismos fundamentales en la configuración discursiva del tráiler. A través de ésta, los avances estructuran la información de la película que se presenta al espectador con el objetivo de llamar la atención sobre el estreno de un nuevo film. Dentro de la temporalidad narrativa se estudia el orden, la duración y la frecuencia.

\subsection{Orden}

El primer nivel que se estudia en el análisis de la temporalidad es el orden, que se refiere a la estructura temporal empleada para narrar la historia. La ordenación que se impone en los trailers analizados es lineal, es decir, el relato desarrolla la historia de manera cronológica. Son discursos con una estructura sincrónica, es decir, el orden del relato obedece el desarrollo cronológico de los acontecimientos. Esta tendencia hacia la linealidad en la estructura temporal de los avances puede explicarse por la exigencia de simplicidad y concreción en la transmisión de los datos de la historia que impone la brevedad de los tráileres. La linealidad en el desarrollo temporal de los acontecimientos se relaciona con la tendencia en la creación de mensajes promocionales hacia los modos de narración más clásicos o hacia lo que Casetti y Di Chio (1991: 211) denominan narración fuerte.

A pesar de que linealidad se convierte en la estructura narrativa preponderante, la totalidad de los trailers analizados ofrece en su relato ejemplos de anacronías, es decir, 
los acontecimientos en la historia son mostrados en el relato alterando en momentos precisos su desarrollo cronológico. Las anacronías se presentan en forma de analepsis y prolepsis. En este caso la reordenación de los acontecimientos en el plano del relato tiene motivaciones retóricas.

Así, todos los tráileres analizados muestran en su representación temporal analepsis, que representan una evocación de un acontecimiento anterior al momento en que se encuentra el relato. Éstas que dotan de coherencia interna al discurso de la historia. Las analepsis son determinantes en los avances que basan su efectividad en el género cinematográfico, pues la repetición que implica este tipo de anacronía (como recuperación de acontecimientos pasados) sitúa la película en un punto reconocible para el espectador a través de la repetición.

El término prolepsis supone un salto al futuro con respecto al tiempo de referencia, es decir, representa un mecanismo de anticipación en el plano del relato que avanza acontecimientos de la historia. Se trata de un elemento fundamental en el tráiler cinematográfico pues se vincula a la naturaleza promocional de éste. El propio avance cinematográfico constituye por sí mismo una suerte de anticipación destinada a suscitar el deseo o interés del espectador sobre un acontecimiento que tendrá lugar en un futuro y que implica a otro texto distinto, el estreno de la película promocionada. La finalidad del tráiler tiene un carácter prolíptico.

\subsection{Duración}

Uno de los elementos fundamentales en la construcción del relato del tráiler cinematográfico es la duración, que determina la relación entre la duración asignada en la historia y en el relato. La brevedad del tráiler como pieza promocional determina que los mecanismos de duración temporal más empleados sean los se encaminan a la reducción temporal (sumarios y elipsis principalmente). A pesar de esto, como se ha podido comprobar en la parte analítica, existen mecanismos recurrentes de expansión temporal en los avances como la pausa y la digresión reflexiva y otros como la cámara lenta y la ampliación que se relacionan con el género de la acción al resaltar la espectacularidad de las imágenes.

\subsection{Contracción temporal}

La elipsis y el sumario son los principales mecanismos de contracción temporal que emplean los avances cinematográficos para ofrecer en menos de tres minutos de duración parte de la trama de la película anunciada, establecer su programa narrativo y presentar la trama del personaje principal y, en algunas ocasiones, algunas subtramas de los personajes secundarios.

La fragmentación y la economía narrativa de este tipo de discurso audiovisual encuentran en la elipsis una herramienta imprescindible para hacer avanzar la acción y omitir contenidos de la película que no cumplen la función retórica o motivacional del tráiler. Isidro Moreno (2003: 68) afirma que el relato publicitario audiovisual por norma general tiende al empleo de la elipsis, "ya que su duración limitada hace que la elipsis sea uno de los fundamentos temporales que utilizan los publicistas para condensar el relato en menos de un minuto y hasta en cinco o diez segundos". 
El tipo de elipsis que tiene una mayor relevancia en la técnica discursiva del tráiler es la elipsis narrativa. Se trata de un silencio textual (y por lo tanto del texto narrativo) de unos acontecimientos que han tenido lugar en la diégesis (Gaudreault y Jost, 1995: 129) y que el espectador ignora. Las elipsis narrativas se convierten en la estrategia fundamental del discurso del tráiler al generar las lagunas necesarias en el espectador y provocar en él un estado de no plenitud que debe conducirle a ver la película que se promociona.

El sumario es junto a la elipsis el mecanismo de contracción temporal más relevante en los avances cinematográficos. Aparece en la totalidad de los trailers examinados. En el sumario se resume una serie de acontecimientos de la historia mostrando aquellos aspectos que representan la globalidad de lo acontecido (Canet y Prósper, 2009: 256). El tráiler puede considerarse un sumario en sí mismo ya que, como se ha constatado a lo largo de la investigación, el avance cinematográfico forma una unidad narrativa autónoma relacionada de manera transtextual con la película que promociona.

\subsection{Expansión temporal}

Resulta obvio afirmar que la expansión temporal es un mecanismo menos frecuente en la articulación discursiva del tráiler de cine. A pesar de esta economía expresiva, los avances recurren a diversos mecanismos que consisten en hacer que la duración del tiempo del relato sea mayor que la duración del tiempo de la historia. Algunos de estos mecanismos, como la dilatación o la cámara lenta, se emplean puntualmente para destacar la espectacularidad de las imágenes. Otro de los mecanismos de expansión temporal, la digresión reflexiva, tiene mayor relevancia para el análisis textual del tráiler ya que se convierte en uno de sus elementos definitorios de este tipo de texto audiovisual al introducir en el discurso del tráiler otro discurso de naturaleza retórica conectado con el carácter promocional de estos textos.

\subsubsection{Digresión reflexiva}

La digresión reflexiva (Genette, 1998: 25-28) incluye aquellas pausas extradiegéticas que pertenecen al relato marco y se vinculan al ámbito de la reflexión o el comentario. La digresión reflexiva introduce en los avances aquellos elementos que se distinguen claramente del discurso principal del tráiler, se trata pues de un "elemento funcionalmente marginal con relación a la historia que domina la narrativa [...] todo discurso que se separa de ese eje dominante; de este modo, una narrativa del nivel hipodiegético" (Reis y Lopes, 1996: 65)

En el tráiler este recurso de expansión temporal adquiere gran relevancia porque introduce en el discurso dos tipos de referencias. En primer lugar, aporta informaciones clave de la película que promociona como el título, los actores principales del reparto, la fecha del estreno o la dirección de la web oficial del filme. Por otra parte, la digresión reflexiva puede aportar información de tipo valorativa que se vincula directamente al apelar a la novedad o al interés del argumento de la película que se promociona. Además, representan pausas discursivas que dotan a los avances de un ritmo característico. 


\subsubsection{Pausa}

La pausa es otro de los mecanismos de expansión temporal con mayor presencia en la configuración narrativa del tráiler y es determinante en el planteamiento rítmico de los avances. Se trata de un mecanismo temporal cuya finalidad en los avances es la de generar la ralentización puntual del discurso dotando así de un ritmo característico a estos avances que se conforman a partir de aceleraciones y ralentizaciones.

\subsubsection{Expansión y reducción temporal a través de efectos especiales}

El empleo de la cámara rápida y de la cámara lenta son otros de los elementos de manipulación temporal recurrentes en los tráileres estudiados. El primero de ellos, la cámara rápida, provoca la contracción temporal del relato y genera la sensación de que un determinado acontecimiento se muestra a una velocidad mayor que en la diégesis. Por otro lado, la cámara lenta, genera la ralentización de la imagen, lo que provoca la expansión temporal del relato. En el caso del tráiler cinematográfico ambos elementos se dirigen a destacar la espectacularidad de determinadas escenas, por lo que los recursos de expansión y reducción temporal mediante efectos audiovisuales se asocian a los avances de las películas de acción y de ciencia ficción.

\subsection{Frecuencia}

La frecuencia establece la relación entre el número de veces que un determinado acontecimiento sucede en la historia y el número de veces que este mismo acontecimiento se muestra en el relato. La frecuencia se convierte en un mecanismo fundamental en el tráiler para dosificar y resaltar determinadas informaciones del discurso. Siguiendo la clasificación que establecen Canet y Prósper (2009: 283), es posible diferenciar hasta cinco tipos de relaciones de frecuencia entre la historia y el relato: frecuencia singulativa, singulativa múltiple, repetitiva, iterativa y cero.

La articulación temporal de los trailers analizados presenta de manera general una frecuencia singulativa. Los trailers narrativos evitan, en términos globales, las repeticiones de imágenes y acciones que extienden el relato y dificultan la codificación del mensaje persuasivo del avance. A pesar de esto, existen numerosos ejemplos de las otras modalidades de frecuencia que atienden a criterios principalmente retóricos.

Así, las frecuencia singulativa múltiple y repetitiva ofrecen en el relato de forma reiterada elementos que se vinculan al género al que pertenece la película promocionada. Estas dos modalidades de frecuencia permiten al discurso del avance insistir en las convenciones visuales y narrativas en las que se basan los géneros cinematográficos como conceptos sintéticos (Dornaleteche, 2009: 178). Ambas frecuencias, la singulativa múltiple y la repetitiva, refuerzan en el discurso del tráiler cinematográfico el sistema de expectativas que generan en el espectador ideas previas acerca del contenido que se van a encontrar en función del género al que pertenece la película promocionada.

El relato iterativo es otra de las modalidades de frecuencia más observada en los avances estudiados. Suele corresponder al inicio del tráiler y su finalidad es ofrecer el marco espacio-temporal en el que se desarrolla la acción que ofrece el tráiler. La frecuencia iterativa ayuda a condensar la acción por lo que le sirve al tráiler como mecanismo de reducción temporal. 
Otra de las modalidades de frecuencia que resulta determinante en la dosificación de la información en el discurso de los avances es la frecuencia cero. El relato cero, que representa una omisión de acontecimientos, se convierte en una herramienta fundamental para generar el suspense en el espectador. La frecuencia cero estimula en el espectador el deseo por experimentar estas experiencias al evitar la consecución completa de éstas experiencias en el discurso del avance. Se trata de un mecanismo que provoca un estado de no plenitud o incertidumbre al generar los vacios necesarios en el tráiler que la audiencia buscará completar con más información.

\section{Conclusiones}

Tal y como afirman los profesionales del marketing cinematográfico, la tendencia actual en el mercado es que los tráileres ofrezcan cada vez más información sobre el contenido de la película. Este fenómeno, conocido como el «tráiler destripa-películas» se fundamenta en la idea ya consolidada de que los tráileres que más contenido muestran de la película obtienen mejores resultados en los test previos de mercado. Así, el objetivo fundamental del tráiler se basa en la estimulación del interés del espectador fundamentada en la presentación progresiva de los elementos más relevantes de la trama de la película, a la vez que se plantean lagunas de conocimiento en el espectador mediante el montaje discontinuo.

Estas ideas se relacionan a su vez con el alto grado de metonimización o condensación narrativa presente en la mayoría de los tráileres actuales. La manipulación temporal es uno de los mecanismos más importantes en la creación del relato del tráiler para poder articular la información que desea presentarse sobre el film de forma atractiva para el espectador. Es principalmente a través de la estructura temporal como se dota del sentido al relato del tráiler: Mediante los diversos mecanismos temporales, el tráiler avanza, pospone, omite, sintetiza, condensa, dilata, expande o detiene elementos de la historia en función de las estrategias retóricas seleccionadas.

El análisis efectuado de la temporalidad de los tráileres más valorados por la industria cinematográfica en los Golden Trailers indica que la fragmentación narrativa del discurso, en la que se fundamenta la articulación discursiva del tráiler, origina la configuración de un nuevo tiempo narrativo propio y característico del avance cinematográfico que emplea mecanismos estables dirigidos a la seducción de espectador.

\section{Referencias bibliográficas}

CANET, Fernando y PRÓSPER, Josep (2009): Narrativa audiovisual. Estrategias y recursos. Madrid, Síntesis.

CASETTI, Francesco y DI CHIO, Federico (1991): Cómo analizar un film. Barcelona, Paidós.

DORNALETECHE, Jon (2007): "Definición y naturaleza del tráiler cinematográfico", en Pensar la publicidad, vol. I, n 2, pp. 99-116. Disponible en http://revistas.ucm.es/inf/18878598/articulos/PEPU0707220099A.PDF Consultado el 27 de julio de 2011. 
DORNALETECHE, Jon (2009): Pensamiento narrativo y retórica en los tráilers cinematográficos. Tesis doctoral. Valladolid, Universidad de Valladolid.

GAUDREAULT, André y JOST, François (1995): El relato cinematográfico. Barcelona, Paidós.

GENETTE, Gérard (1998): Nuevo discurso del relato. Madrid, Cátedra.

MORENO, Isidro (2003): Narrativa audiovisual publicitaria. Barcelona, Paidós.

REGOSA, Maurizio (2003): Per un'analisi del Trailer Cinematografico. Firenze: Alinea.

REIS, Carlos y LOPES A. Cristina (1996): Diccionario de narratología. Salamanca, Colegio de España.

\section{Eva GIL PONS}

eva.gil@udc.es

Universidade da Coruña

Licenciada en Comunicación Audiovisual por la Universidad de Valencia, actualmente desarrolla su tesis doctoral sobre la narrativa del tráiler cinematográfico. Ha impartido clases de Narrativa Audiovisual y actualmente colabora en la docencia de las materias de Ficción Audiovisual y Comunicación Oral y Escrita en la Universidade da Coruña. 